\title{
Tubercular Breast Lesion A Great Mimicker of Carcinoma Breast
}

\author{
Kumar BNK ${ }^{1}$, Pandya B ${ }^{1}$, Das $D^{1}$, Shreeramulu PN $^{2}$ \\ ${ }^{1}$ Department of Radio-diagnosis, ${ }^{2}$ Department of Surgery, Sri Devaraj URS medical college, \\ Kolar-563101, India
}

\begin{abstract}
Breast tuberculosis is uncommon entity with confusing clinical, radiological and even microbiological presentation which is often misdiagnosed as breast carcinoma or breast abscess. ${ }^{1}$ A 28 year old female patient presented with a swelling in outer quadrant of left breast which resembled carcinoma of breast but on ultrasound a hypoechoic lesion was noted which turned out to be tuberculosis on histopathology. Conclusion: Breast tuberculosis (TB) is a rare disease typically affecting young lactating multiparous women and can present either as an abscess or as a unilateral, painless breast mass which can easily be confused with carcinoma. $^{2,3}$
\end{abstract}

Keywords: Breast abscess, Hypoechoic, Mammography, Tuberculosis.

\section{Introduction}

Breast tuberculosis is uncommon entity with confusing clinical, radiological and even microbiological presentation which is often misdiagnosed as breast carcinoma or breast abscess. Primary breast tuberculosis is rare even in countries where the incidence of pulmonary and extrapulmonary tuberculosis is high. ${ }^{4}$ Breast tuberculosis commonly affects women in their reproductive age group, between 21-30 yr. This may be because the female breast undergoes frequent changes during the period of activity and is more liable to trauma and infection .It is

Correspondence to: Dr. Bhargav Pandya, Diploma in Radiodiagnosis - Sri Devaraj URS medical college, Kolar-563101, India Email Id: drbhargav83@gmail.com however postulated that the incidence of primary breast tuberculosis may rise with the increasing number of AIDS cases.

\section{Case Report}

A 28 year old female presented with a palpable non -tender swelling in the left upper outer quadrant of left breast since three months duration. The patient did not have fever, weight loss or any releant past medical history. It was immobile and hard swelling. The surrounding skin was warm to touch and mildly oedematous. There was no discharging sinus. On ultrasound, a hypo echoic well defined lobulated oval mass lesion with an anechoic cystic area in the left upper-outer quadrant measuring approximately $3.5 \times 2.4 \mathrm{~cm}$ was noted. The cystic area measured about $7 \mathrm{x} 7 \mathrm{~mm}$. There 
was mild surrounding architectural distortion but no calcifications were noted. On mammography a dense lobulated breast lesion was noted in the left upper-outer quadrant.

Based on imaging findings the mass was highly suspicious for malignancy and ultrasound guided breast biopsy was suggested. On biopsy it turned out to be a granulomatous lesion of tubercular etiology.
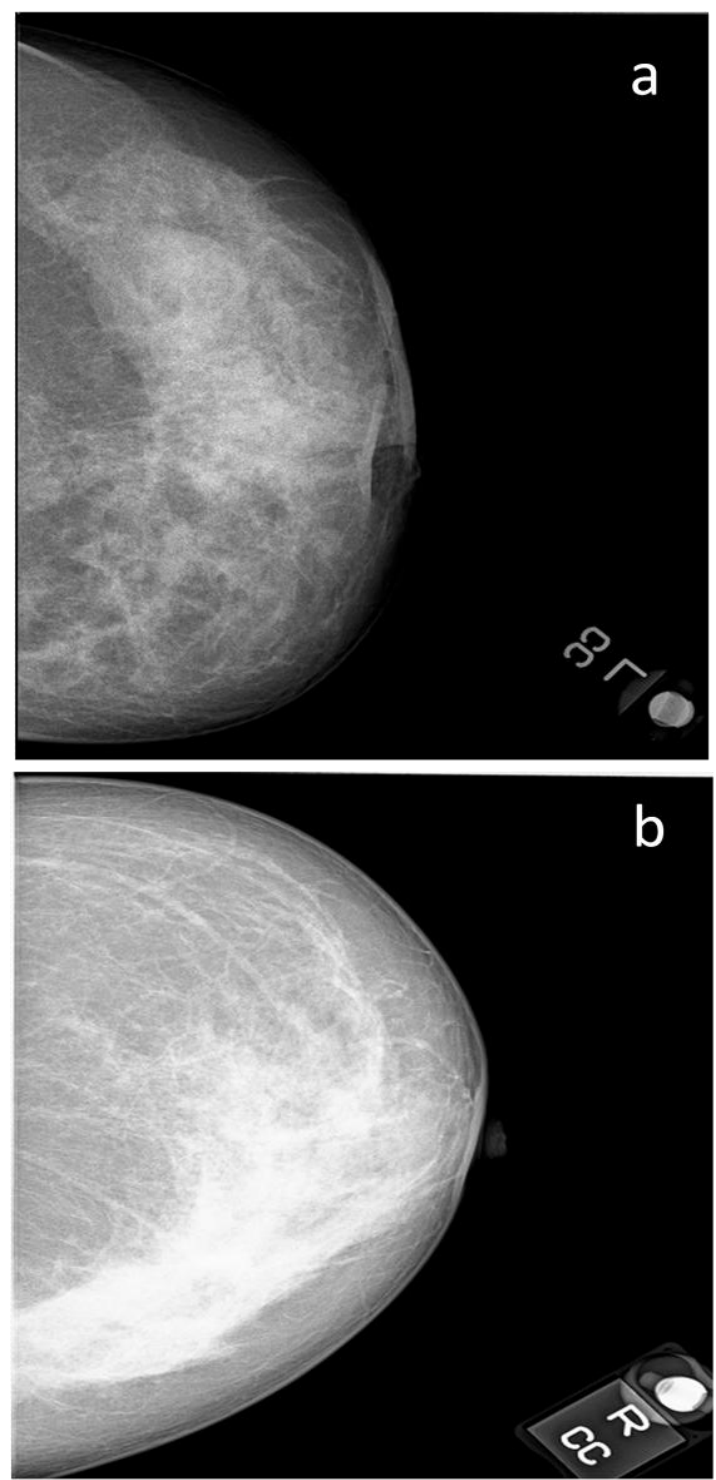

Fig. 1a (left breast) and 1b (right breast): Mammography cranio-caudal view showing ill defined sclerosing lesioninvolving the left breast as seen in fig 1a. Fig $1 \mathrm{~b}$ shows the normal right breast.

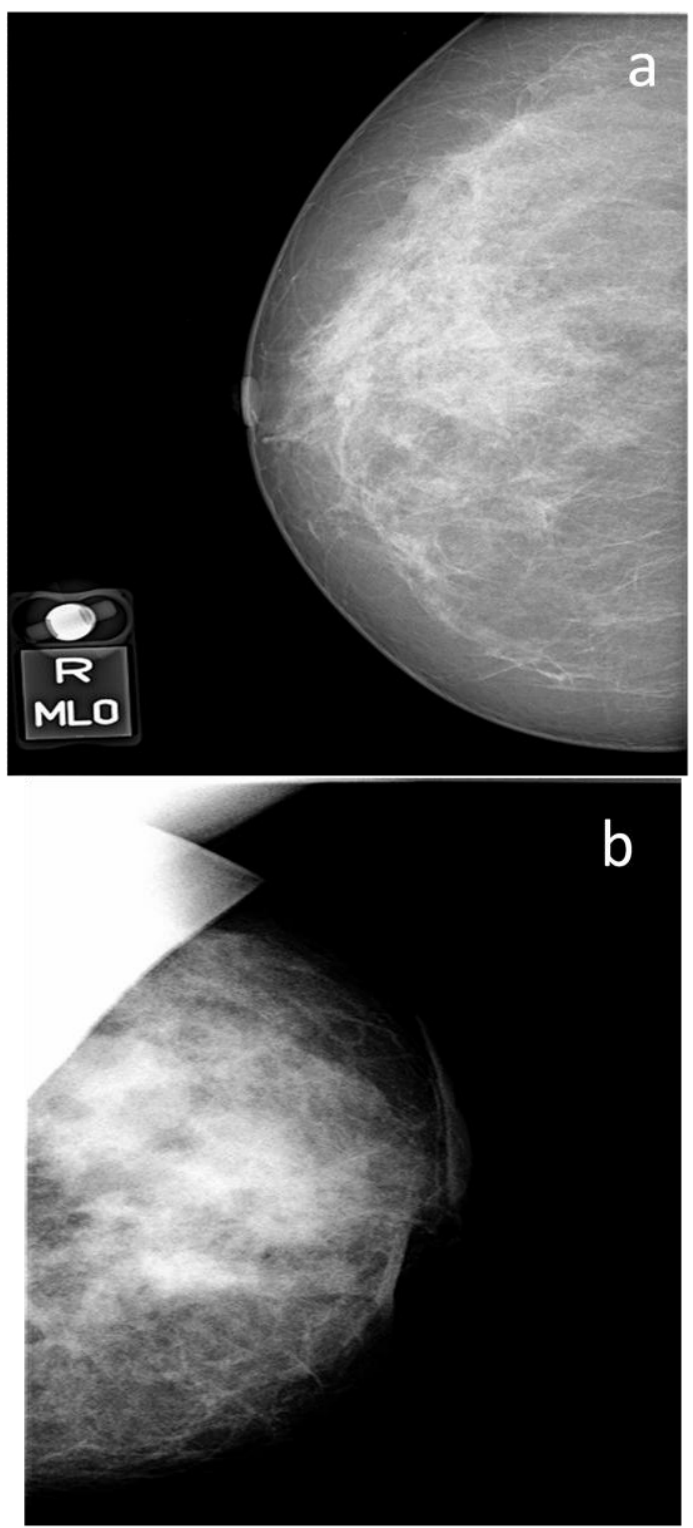

Fig. 2a (right breast) and Fig 2 b (left breast): Mammography in MLO view. Right breast appears to be normal whereas left breast shows a dense illdefined lesion in the upper quadrant, lesion was considered highly suspicious for malignancy.

\section{Discussion}

In the abscence of well-defined clinical features, the true nature of the disease remains obscure and it is often mistaken for carcinoma or pyogenic breast abscess. ${ }^{5}$ It also presents a diagnostic problem on radiological and microbiological 

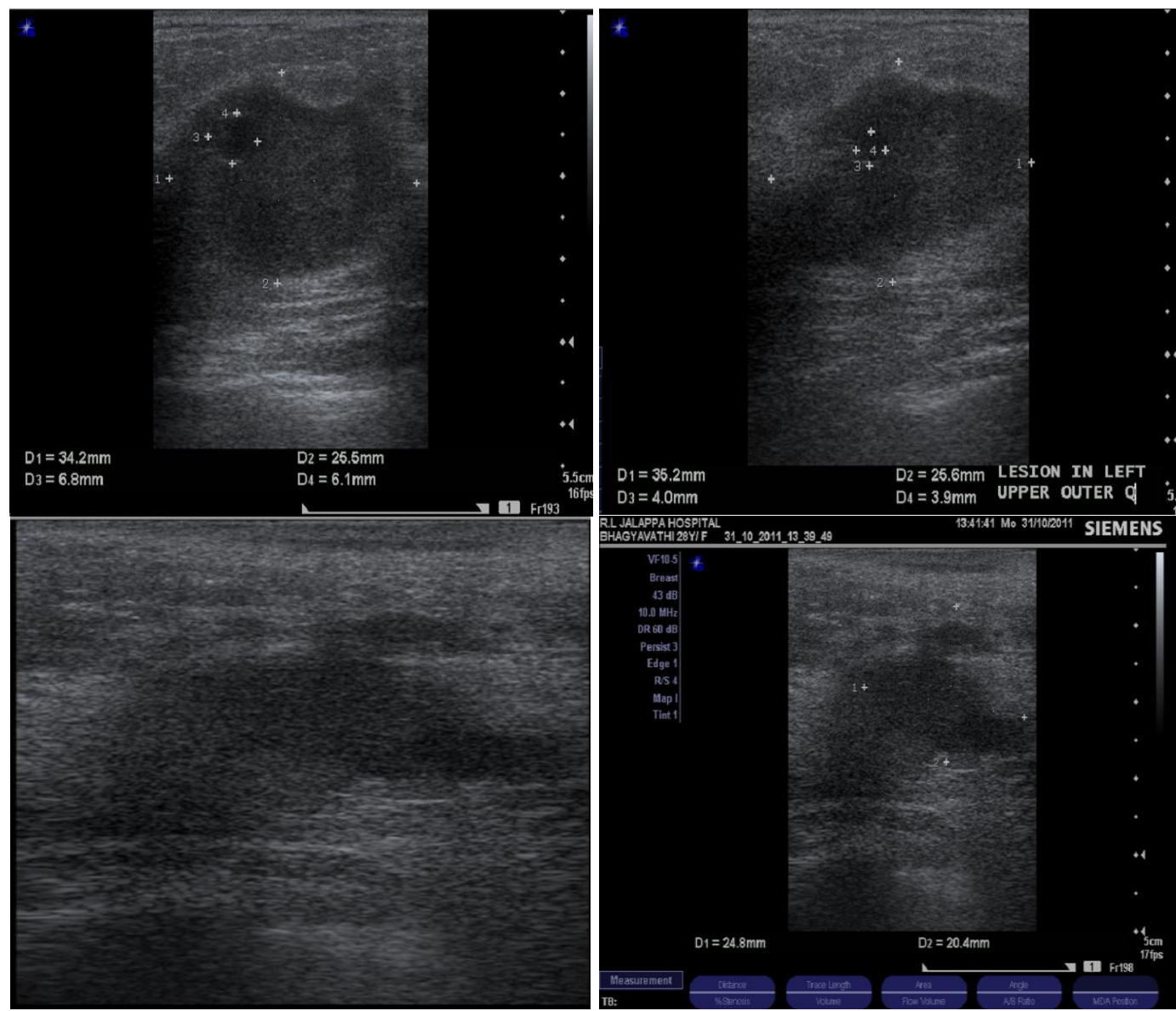

Fig. 3: Ultrasonographic images of the left breast showing an irregular ill defined lesion with surrounding breast tissue architechtural distortion.

investigations and thus high index of suspicion acquires an important position. In mammography, three different patterns are recognized. The first one is nodular pattern; which is indicated by well-circumscribed, painless, slow growing lesions. Next is disseminated pattern in which focal lesions are connected to each other in addition to skin thickening and sinus formation. The third is sclerosing pattern, which is seen mostly in older women as slow growing, dense fibrous tissue. Generally, there is no microcalcification or nipple retraction. According to radiological findings, nodular pattern can be mistaken for fibroadenoma or carcinoma, disseminated pattern for inflammatory carcinoma, and sclerosing pattern for scirrhous carcinoma. In our case, mammography findings were consistent with sclerosing pattern. Caseating epitheloid cell granulomas in the tissue samples were diagnostic of tuberculosis.

\section{Conclusion}

Breast tuberculosis (TB) is a rare disease its incidence ranges $^{6}$ between $0.1 \%-0.52 \%$, typically affecting young lactating multiparous women and can present either as an abscess or as a unilateral, painless breast mass. Breast TB is paucibacillary and consequently tests such as microscopy, culture and nucleic acid amplification tests such as polymerase chain reaction techniques do not have the same diagnostic utility as 
they do in pulmonary tuberculosis. ${ }^{7}$ Thus, it is not uncommon for breast $\mathrm{TB}$ to be misdiagnosed either as non-specific abscess or carcinoma. It is important that breast tuberculosis is detected ${ }^{8}$ as highly effective antitubercular drugs are available and even more importantly the patient is spared of any unnecessary surgical intervention.

\section{References}

1. Zandrino F, Monetti F, Gandolfo N. Primary tuberculosis of the breast. A case report. Acta Radiologica 2000;41:61-63.

2. Schnarkowski P, Schmidt D, Kessler M, Reiser MF. Tuberculosis of the breast. US, mammographic and CT findings. J Comput Assist Tomogr 1994;18:970971.

3. Crowe DJ, Helvie MA, Wilson TE. Mammographic and sonographic findings with clinical correlations. Invest Radiol 1995;30:582-587.

4. Madhusudhan KS, Gamanagatti S. Primary breast tuberculosis masquerading as carcinoma. Singapore Med J 2008;49:3-5.

5. Akcakaya A, Eryilmaz R, Sahin M, Ozkan O. Tuberculosis of the Breast. The Breast Journal 2005;11:85-86.
6. Tewari M, Shukla HS. Breast tuberculosis: diagnosis, clinical features and management. Indian $\mathrm{J}$ Med Res 2005;122:103-110.

7. Pai M, Riley LW, Colford JM., Jr Interferon-gamma assays in the immunodiagnosis of tuberculosis: a systematic review. Lancet Infect Dis 2004; 4:761.

8. Morino GF, Rizzardi G, Gobbi F, Baldan M. Breast tuberculosis mimicking other diseases. Tropical Doctor 2007;37:177178.

9. Mirsaeidi SM, Masjedi MR, Mansouri SD, Velayati AA. Tuberculosis of the breast: report of 4 clinical cases and literature review. East Mediterranean Health J 2007;13:670-6.

10. Harold FH, Thomas HR. Mammary tuberculosis. J Royal Soc Med 1982; 75:764-5.

11. Tewari M, Shukla HS. Breast tuberculosis: diagnosis, clinical features and management. Indian $\mathrm{J}$ Med Res 2005;122:103-10. 